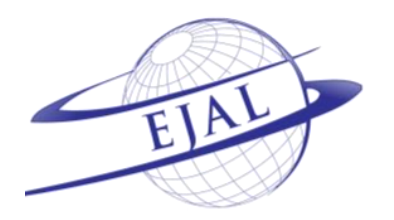

Available online at www.ejal.eu

\title{
Review of Thinking English Translation: Analysing and Translating English Source Texts
}

\author{
Cüneyt Demir a * (D) \\ a Siirt University, Kezer Campus, Siirt, 56100, Turkey
}

Received 19 November 2018 | Received in revised form 01 January 2019 | Accepted 03 January 2019

\begin{abstract}
APA Citation:
Demir, C. (2019). Review of Thinking English Translation: Analysing and Translating English Source Texts. Eurasian
\end{abstract} Journal of Applied Linguistics, 5(1), 181-184. Doi: 10.32601/ejal.543797

\begin{abstract}
Thinking English Translation: Analysing and Translating English Source Texts, Stella Cragie and Ann Pattison. Routledge, Oxon / New York (2018). 134 pp., Paperback: £23.99, Hardback: £88.00, ISBN: 978-1-138-71394-9

(C) 2019 EJAL \& the Authors. Published by Eurasian Journal of Applied Linguistics (EJAL). This is an open-access article distributed under the terms and conditions of the Creative Commons Attribution license (CC BY-NC-ND) (http://creativecommons.org/licenses/by-nc-nd/4.0/).
\end{abstract}

Keywords: translation; fast-track; analysis; languages; texts

This book is a welcome contribution to the existing body of research into translation studies. It is a helpful source for instructors of translation courses as well as advanced undergraduate and postgraduate students. The nearest resource it could be compared to is James's (2012) Interpretation: Techniques and Exercises which provides more detailed information on translation techniques for different discourses. Inside a continuum of research, evaluation, and theorizing in translation studies, this book offers implementation samples through authentic translation examples.

The book is organised into four chapters with a brief preface provided by the authors. One useful feature of the book is that the chapters follow a line from theoretical knowledge of translation to practical implementations. This allows readers to get background knowledge on translation methodologies before translation practices, though there is still room for pre-translation preparations. A glossary and an index are provided at the end of the book. The first chapter includes criteria before initiating translation; the second chapter informs readers on some grammar points, and draws readers' attention to various factors that may affect the quality of translation. The third and fourth chapters include practical activities through readymade translation examples from different languages. In brief, the chapters fall largely into two categories: theoretical and applied; the first two chapters explore

\footnotetext{
* Corresponding author Tel.: +90-505-937-4345

E-mail address: cuneytdemir@siirt.edu.tr
} 
ideas and theories whilst the last two chapters intend to put theoretical knowledge into practice.

Chapter One, the longest chapter, aims to establish a general framework for pretranslation analysis; i.e., it informs readers on what to know before starting a translation process, which includes three phases: pre-translation reading, intranslation reading, and post-translation reading. Having indicated the importance of understanding the source text, the authors define the criteria of pre-translation analysis through explanations of specific terms and example tasks for readers. The criteria that the authors mentioned are subject matter, purpose of the translation, genre, format, language related matters like grammar, vocabulary choice, discursive features, organization of the translation, meaning, viewpoint, and culture and context. The explanations of these criteria for pre-translation analysis may help readers to create their own path in the process of prospective translations. At the end of the chapter the authors provide a useful summary of the chapter. Also, key terms are presented to familiarize the readers. The chapter is good for readers to develop an analytical preview of translation.

Chapter Two mentions the importance of unique attributes that every language holds in its structure as every language has its own distinctive features to be taken into consideration throughout translation process like grammatical, lexical and pragmatic (appropriate use of language in context) differences. It is underscored that there is not an eclectic method that could be applied to all translation work; therefore, each translation work is to be regarded as a unique work that necessitates customized translation implementations. Being aware of the importance that register and genre of a source text may have on the target text, the authors provides translation samples from different registers such as recent and older texts, information and advice, specialist and technical, fiction and non-fiction, and newspaper and magazine articles; accordingly talks about the challenge that a translator may encounter if s/he is not qualified in the register that the translation is carried out. In other words, any registers that fall outside the translator's specialization may affect the quality of the translation, which is why familiarization with genres and registers is of utmost importance for the translation quality. At the end of the chapter, some practical tips on how to overcome the challenges that the context and registers have posed are suggested.

Chapter Three provides authentic samples to illustrate the problems that a translator may encounter in the process of translation. It is aimed at developing a practical approach to source text analysis so that more informed, coherent and appropriate target text may be created. To this purpose, the authors introduce a technique that they have developed; fast-track analysis. The issues that are related to establishing the theoretical foundation of pre-translation analysis in the first chapter are put into practice through the implementation of the technique. The validity and efficiency of the technique is tested through authentic translation samples so that its merits could be witnessed by the readers. This technique is based on two questions: what and how. What questions allow the translator to categorize the source text, thus 
understand the small details that should not be overlooked (e.g. what type of text is it?) whilst how questions offer possible ways that the translator may follow in the process of translation (e.g. How is the discourse organised?). In the chapter, you may find many samples; first the full sample texts are given, and then the analyses are conducted in line with the pre-translation criteria mentioned in the first chapter.

The final chapter is fully devoted to practical applications. It expands its scope through some examples of texts from languages, namely, Arabic, Chinese, French, Russian and Spanish. The text types include fiction, business, administration, tourism, cookery, science and technology. The chapter can be thought as an application area for ideas and theories covered in the previous chapters. Different from the criteria used for the analyses in Chapter Three (pre-translation criteria), the translation analyses in this chapter are conducted according to two strategies which are macro (concise) and micro (detailed). After presenting the source text in English, the translated text in the target language is provided. Then the translated text are analysed based on macro and micro strategies. The activity is good to be able to show weak and strong sides of the translation. This chapter can be thought as an annotated activity chapter as it entirely includes assessment and evaluations of the sample source texts.

Taken together, the book has many merits. The strong point of this book is that it provides numerous authentic translation samples as well as critiques regarding some translation problems. The book also deserves praise with its originality of developing a technique which eases and accelerates the translation process thanks to the successful pre-translation analysis. As known, one of the problems that students in the Departments of Interpretation and Translation encounter is to create a convenient framework before initializing a translation work (Gutt, 2014). Therefore, this book may help them to establish a pre-translation framework for a better understanding of how to approach source texts and where to start. On the whole, the book widens our knowledge of analysis skill for translation process. However, there is still room for minor critical remarks. One demerit of the book is the lack of theoretical information on translation studies. Theoretical information is important in constructing practical knowledge on it. Furthermore, the last chapter is absolutely beneficial, though it would be better if there were not samples from so many different languages since the authors miss providing enough explanation for each sample due to number of languages. The struggle for providing examples as varied as possible is absolutely praiseworthy; however, the number of the samples from each language is not sufficient in understanding the basics of techniques mentioned in the Chapter Three because only a few examples from different languages do not appear to be enough to get the technique. Accordingly, a welcome addition for this book would simply be the suggestion that the authors focus on two languages with most translated text (namely English and French) rather than five languages so that more detailed evaluations and samples could be presented for the readers. The last addition is that more examples regarding the use of the developed technique on each language may help readers be more practical in applying the technique in their own studies. 
These minor shortcomings should not detract from the positive contribution that this book makes to the translation studies. Thinking English Translation: Analysing and Translating English Source Texts is valuable for anyone; particularly for instructors who need a practical course book for their undergraduate students. I also recommend this book for freelance translators, who make translation on different genres, in order to critique their own work.

\section{References}

Gutt, E. A. (2014). Translation and relevance: Cognition and context. London, UK: Routledge. Nolan, J. (2012). Interpretation: Techniques and exercises (Professional interpreting in the Real world). Salisbury: MPG Books Group.

\section{Copyrights}

Copyright for this article is retained by the author(s), with first publication rights granted to the Journal. This is an open-access article distributed under the terms and conditions of the Creative Commons Attribution license (CC BY-NC-ND) (http://creativecommons.org/licenses/by-nc-nd/4.0/). 